\title{
Failure characteristics of rainfall-induced shallow landslides in granitic terrains of Shikoku Island of Japan
}

\author{
Ranjan Kumar Dahal · Shuichi Hasegawa · \\ Atsuko Nonomura · Minoru Yamanaka · \\ Takuro Masuda $\cdot$ Katsuhiro Nishino
}

Published online: 25 October 2008

(c) Springer-Verlag 2008

\section{Erratum to: Environ Geol}

\section{DOI 10.1007/s00254-008-1228-x}

Unfortunately, errors occurred in Table 4 (in row arrangement) and Fig. 12 (position of threshold lines of
Guzzeti et al. 2007). The corrected Table 4 and Fig. 12 are given below.

Table 4 Result of stability analyses for different saturated fractions of the masa soil layer

\begin{tabular}{|c|c|c|c|c|c|c|c|c|}
\hline \multicolumn{2}{|l|}{ Landslide no. } & A-5 & A-I2 & B-7 & B-8 & B-9 & $\mathrm{C}-7$ & D-14 \\
\hline \multicolumn{2}{|l|}{ Slope angle $\left(^{\circ}\right)$} & 34 & 38 & 44 & 41 & 43 & 32 & 38 \\
\hline \multicolumn{2}{|c|}{ Factor of safety for dry conditions } & 1.44 & 1.22 & 1.18 & 1.38 & 1.32 & 1.65 & 1.29 \\
\hline \multicolumn{9}{|c|}{ Factor of safety for wet conditions } \\
\hline \multirow[t]{7}{*}{ Saturated fraction } & 0.4 & - & 1.00 & 1.02 & - & - & - & - \\
\hline & 0.5 & 1.13 & 0.96 & 0.98 & 1.11 & 1.07 & 1.28 & 1.02 \\
\hline & 0.6 & 1.08 & 0.92 & 0.95 & 1.08 & 1.04 & 1.23 & 0.97 \\
\hline & 0.7 & 1.03 & 0.88 & 0.91 & 1.04 & 1.00 & 1.17 & 0.93 \\
\hline & 0.8 & 0.98 & 0.84 & 0.88 & 1.00 & 0.97 & 1.12 & 0.89 \\
\hline & 0.9 & 0.93 & 0.79 & 0.85 & 0.96 & 0.93 & 1.06 & 0.85 \\
\hline & 1.0 & 0.88 & 0.75 & 0.81 & 0.92 & 0.90 & 1.00 & 0.81 \\
\hline
\end{tabular}

The online version of the original article can be found under doi: 10.1007/s00254-008-1228-x.

R. K. Dahal - S. Hasegawa - A. Nonomura - M. Yamanaka

T. Masuda

Department of Safety Systems Construction Engineering,

Faculty of Engineering, Kagawa University,

2217-20, Hayashi-cho, Takamatsu City 761-0396, Japan

R. K. Dahal ( $\square)$

Department of Geology, Tri-Chandra Multiple Campus,

Tribhuvan University, Ghantaghar, Kathmandu, Nepal

e-mail: ranjan@ranjan.net.np

URL: http://www.ranjan.net.np

K. Nishino

Ichigaya Building, Oyo Corporation,

4-2-6, Kudan North, Chiyoda, Tokyo 102-0073, Japan 


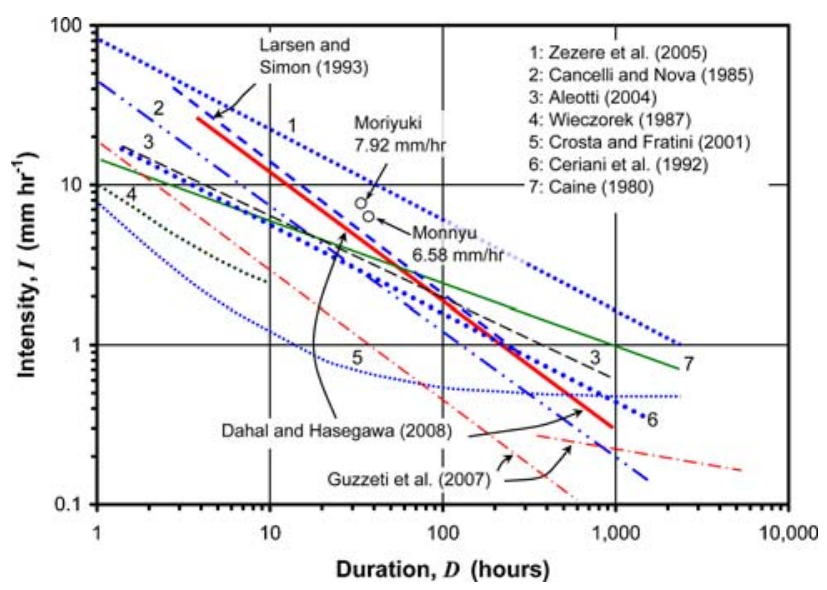

Fig. 12 Rainfall intensity and duration associated with slope failures during typhoon 0423 (Tokage) in northeast Shikoku, Japan, and curves proposed by various researchers for a similar case. From the data of 2004 landslides events, threshold rainfall intensity for northeast Shikoku is slightly higher than the threshold lines for rainfall triggering landslides proposed by Larsen and Simon (1993) for Puerto Rico (humid tropical region) and by Dahal and Hasegawa (2008) for the Nepal Himalaya (tropical monsoon region). Similarly, it is slightly lower than threshold for landslides in Portugal, western Europe (Zezere et al. 2005) 